\title{
The ETS oncogene family transcription factor FEV identifies serotonin-producing cells in normal and neoplastic small intestine
}

\author{
Yu-cheng Wang ${ }^{1,2}$, Marlene B Zuraek ${ }^{1,2}$, Yasuhiro Kosaka ${ }^{3}$, Yasuharu Ota ${ }^{3}$, \\ Michael S German '3,4, Evan S Deneris ${ }^{5}$, Emily K Bergsland',4, David B Donner', , \\ Robert $S$ Warren ${ }^{1,2}$ and Eric K Nakakura ${ }^{1,2}$
}

\footnotetext{
${ }^{1}$ UCSF Helen Diller Family Comprehensive Cancer Center, ${ }^{2}$ Department of Surgery, ${ }^{3}$ Hormone Research Institute, Diabetes Center and ${ }^{4}$ Department of Medicine, University of California, 1600 Divisadero Street, A-724, San Francisco, California 94143-1932, USA ${ }^{5}$ Department of Neurosciences, Case Western Reserve University School of Medicine, Cleveland, Ohio, USA

(Correspondence should be addressed to E K Nakakura at Division of Surgical Oncology, Department of Surgery, UCSF Helen Diller Family Comprehensive Cancer Center, University of California; Email: eric.nakakura@ucsfmedctr.org)
}

\begin{abstract}
Neuroendocrine (NE) or carcinoid tumors of the small intestine (SI) frequently metastasize and produce the hormone serotonin, causing significant morbidity and mortality. A member of the ETS oncogene family of transcription factors, Fev, acts with the homeodomain transcription factor Nkx2.2 in the development of serotonin neurons in mice. In this study, we investigated the role of Fev in normal and neoplastic SI. In NE tumors (NETs) of the SI, serotonin stimulates tumor growth and causes debilitating symptoms, such as diarrhea, flushing, wheezing, and rightsided valvular heart disease (i.e. carcinoid syndrome). Compared with those in the matched normal human SI, FEV expression levels were significantly elevated in primary NETs (20-fold, $P<0.0001$ ), lymph node metastases (35-fold, $P=0.004$ ), and NET liver metastases (22-fold, $P<0.0001)$ resected from patients with serotonin excess. Fev is expressed in the wild type but not in Nkx2.2 (-/-) mouse SI, in which cells producing serotonin are absent. Using recombinationbased cell lineage tracing, we found that FEV-positive cells give rise to serotonin-producing cells in the SI. In Fev (-/-) mouse SI, we observed no difference in the number of cells producing serotonin or other hormones. We conclude that FEV expression identifies serotoninproducing cells in normal and neoplastic SI and is a novel target for diagnosis of patients with NETs of the SI.
\end{abstract}

Endocrine-Related Cancer (2010) 17 283-291

\section{Introduction}

The incidence of neuroendocrine (NE) - or carcinoid tumors has increased over the past 30 years to $2.5-5$ individuals/100 000 per year in the US (Modlin et al. 2003, 2008). The predominant sites of origin for NE tumors (NETs) are the gastrointestinal (GI) and bronchopulmonary systems (Hauso et al. 2008), and within the GI tract, the small intestine (SI) is the most common site (Modlin et al. 2007). For most patients with GI-NETs, surgery, the only potentially curative treatment, is not possible because of extensive metastatic disease, and survival rates have not improved over 30 years (Modlin et al. 2003, 2007). The NE phenotype is used for diagnosis, and it contributes to tumor-related morbidity and mortality. For example, the NE marker chromogranin A (CHGA) is used for NET diagnosis. Serotonin (5-HT) and other mediators stimulate NET growth and cause debilitating symptoms, such as diarrhea, flushing, wheezing, and right-sided valvular heart disease (i.e. carcinoid syndrome; Ishizuka et al. 1992, von Wichert et al. 2000). Current therapy has limited efficacy in shrinking tumors and is ineffective in palliating symptoms in the long term (Nakakura et al. 2007). Earlier diagnosis and 
more effective therapies are needed, both of which require a better understanding of NET biology.

Although the origin of SI-NETs is not known, they are believed to arise from intestinal stem cells or endocrine cells. In the SI epithelium, multipotent stem cells generate endocrine cells, enterocytes, goblet cells, and Paneth cells (Schonhoff et al. 2004a). The transcription factor Math1 is required for the development of the SI secretory lineage, including endocrine, goblet, and Paneth cells (Yang et al. 2001). Another transcription factor, neurogenin3, initiates NE differentiation in immature cells (Jensen et al. 2000, Jenny et al. 2002, Lee et al. 2002, Schonhoff et al. 2004b). Additional transcription factors, such as Nkx2.2, Gfi1, Pax4, Pax6, NeuroD1, $\mathrm{Pdx} 1$, and Insm1, control the subsequent differentiation of endocrine cell subtypes (Schonhoff et al. 2004a, Shroyer et al. 2005, Gierl et al. 2006, Desai et al. 2008, Wang et al. 2009). Other transcription factors are also likely involved.

Many of the same transcription factors and signaling events that are essential for neuronal differentiation are also required for NE differentiation in normal and neoplastic gut. In the central nervous system (CNS), Nkx2.2, Ascl1, and Fev participate in a transcription factor pathway necessary to generate 5-HT neurons (Cheng et al. 2003, Pattyn et al. 2004). Recently, we and others showed that $\mathrm{Nkx} 2.2$ also functions in normal SI to control NE differentiation, regulating the production of numerous hormones, including 5-HT (Desai et al. 2008, Wang et al. 2009). In addition, we found that Nkx2.2 is expressed in most NETs of the GI tract, including SI-NETs (Wang et al. 2009). We also reported that Ascl1 is expressed in human GI-NETs and that Notch signaling inhibits GI-NET hormone production and growth, via a conserved mechanism present during normal development, wherein Notch activation inhibits the differentiation of gut endocrine cells by inhibiting the expression of pro-endocrine transcription factors (Nakakura et al. 2005).

Whether Fev functions in NE differentiation of normal or neoplastic SI is not known. FEV, also known as Pet-1 (PC12 ETS factor), is a member of the ETS oncogene family of transcription factors (Fyodorov et al. 1998). A chromosomal translocation encoding EWS/FEV or FUS/FEV fusion protein may mediate Ewing's sarcoma development (Peter et al. 1997, Ng et al. 2007), and aberrant FEV expression has been described in malignant pancreatic NETs (Duerr et al. 2008). Fev is necessary for 5-HT neuron development, functioning downstream of Nkx2.2 and Ascl1 (Cheng et al. 2003, Pattyn et al. 2004), and cells that produce
5-HT are the most abundant SI endocrine cell type. In this study, we evaluated the role of FEV in the differentiation of 5-HT-producing cells in normal and neoplastic SI.

\section{Materials and methods}

\section{Animals and human tissues}

Fev, ePet-Cre, and Nkx2.2 transgenic mice were generated, maintained, and genotyped according to the regulations of the IACUC at the University of California San Francisco (UCSF) as described previously (Sussel et al. 1998, Hendricks et al. 2003, Scott et al. 2005). Human tissue samples were obtained from resection specimens after approval by the UCSF Committee on Human Research, which is the institutional IRB (IRB number: H6172-26943-05A).

\section{Histology and immunohistochemistry}

Tissues were fixed in Z-fix (Anatech, Battle Creek, MI, USA) and processed for paraffin or frozen sections as described (Scott et al. 2005, Wang et al. 2009). The following primary antibodies were used: rabbit antigastrin/CCK, which reacts with gastrin and CCK because they share a common carboxy-terminal tetrapeptide sequence necessary for bioactivity (Novocastra, Newcastle, UK), 1:200; goat anti-ghrelin (Santa Cruz Biotechnology, Santa Cruz, CA, USA), 1:800; rabbit anti-CHGA (Immunostar, Hudson, MA, USA), 1:1000; rabbit anti-5-HT (Immunostar), 1:4000; mouse monoclonal anti-5-HT (Dako, Carpinteria, CA, USA), 1:25; goat anti- $\beta$-galactosidase ( $\beta$-gal; Biogenesis, Sandown, NH, USA), 1:2500. Secondary antibodies (Jackson ImmunoResearch, West Grove, PA, USA) were FITCconjugated goat anti-mouse and anti-rabbit, 1:200; FITC-conjugated donkey anti-goat and anti-mouse, 1:200; Cy3-conjugated donkey anti-goat, goat antimouse, and anti-rabbit, 1:400. Slides were imaged on an Axioskop 2 microscope (Zeiss, Thornwood, NY, USA) or on an LSM510 META confocal microscope (Zeiss).

\section{Cell quantification and data analysis}

Multiple sections from the SI (duodenum) from at least three Fev $(+/+)$ and $\mathrm{Fev}(-/-)$ mice were analyzed for each experiment. The number of cells per unit length of intestine was calculated for at least three different mice for each genotype, and a minimum of $15 \mathrm{~mm}$ of intestinal length was analyzed per animal. Results are expressed as mean \pm s.E.M. Mean changes were compared using the Mann-Whitney $U$ test. A value of $P<0.05$ was considered to be statistically significant. 


\section{RNA analysis}

Total RNA was isolated using the RNeasy Mini Kit (Qiagen) from the indicated tissues. First-strand cDNA was prepared from $1 \mu \mathrm{g}$ of total RNA using the SuperScript III First-Strand cDNA Synthesis System (Invitrogen) and a combination of random hexamer and oligo dT primers. For TaqMan real-time PCR amplification, $30 \mathrm{ng}$ of cDNA template were used. Quantity of cDNA template was determined based on the concentration of RNA used for cDNA synthesis which was measured using a spectrophotometer. All primer/probe sets were validated with a standard curve using serial cDNA dilutions. All assays were performed with ABI assay-on-demand and ABI TaqMan Universal PCR Master Mix. Quantification was done using an Opticon2 thermocycler (MJ Research, Waltham, MA, USA) following the manufacturer's instructions. Results were normalized relative to the level of mouse GUS $2 b$ mRNA, which was used as an internal control for cDNA quantity and quality. For RT-PCR analysis the following primers were used: gastrin, 5'-GTGTGTGTGCATGCTAGTCTTAG- $3^{\prime}$ and $5^{\prime}$-GCGACCAAAGTCCATCCATCCG$3^{\prime}$; $C c k, 5^{\prime}$-ACATCCAGCAGGTCCGCAAAG-3' and 5'-CGATGGGTATTCGTAGTCCTC-3'; secretin, $5^{\prime}$-GACGTTCACCAGCGAGCTCAG-3' and 5'-CACTCTGAATGGTCGACAGCA-3 ${ }^{\prime}$; somatostatin, $5^{\prime}$-TCTCTGCTGCCTGCGGACCT- $3^{\prime}$ and $5^{\prime}$-GCCAAGAAGTACTTGGCCAGTTC- ${ }^{\prime}$; glucagon, 5'-ATCATTCCCAGCTTCCCAGA- $3^{\prime}$ and $5^{\prime}$-AGGTTCCTCTTGGTGTTCAT-3'; Tac $1,5^{\prime}$-CGCAATGCAGAACTACGAAA- $3^{\prime}$ and $5^{\prime}$-GCTTGGACAGCTCCTTCATC- $3^{\prime}$; and Gapdh, 5'-CAAAATGGTGAAGGTCGGTGT-3' and $5^{\prime}$-TTCTCCATGGTGGTGAAGACA- $3^{\prime}$. The following TaqMan Gene Expression Assay probes (Applied Biosystems, Foster City, CA, USA) were used: Fev, Mm00462220_m1; GusB, Mm 00446953_m1; Nkx2.2, Mm00839794_m1; Tph1, Mm00493794_m1; ghrelin, Mm00445450_m1; FEV, Hs00232733_m1; and GusB, Hs99999908_m1. Differences in expression levels were compared using the Mann-Whitney $U$ test or the Wilcoxon rank-sum test as appropriate. Significance was set at $P<0.05$ or $P<0.02$ to account for multiple testing using Bonferroni adjustment.

\section{Results}

\section{FEV is expressed in human SI-NETs that produce 5-HT}

To determine whether $F E V$ is expressed in human SI-NETs, we identified 12 patients with well-differentiated SI-NETs for whom tissue was available. All patients had SI-NETs located in the ileum and lymph node metastases, and most (10/12) had liver metastases (Table 1). Every patient exhibited increased tumor 5-HT elaboration, which was evidenced by elevated urinary $24 \mathrm{~h}$ 5-hydroxyindoleacetic acid (5-HIAA) levels (12 of 12 patients; median $=45.6$, range $7.9-520.6$, normal $<6.0 \mathrm{mg} / 24 \mathrm{~h}$ ) and/or the presence of the carcinoid syndrome ( 9 of 12 patients; Table 1). The following three findings are characteristic of SI-NETs: 1) an ileal primary tumor, 2) excessive 5-HT elaboration, and 3) frequent lymph node and liver metastases. None of the patients had multiple endocrine neoplasia (MEN) I syndrome.

FEV expression has been detected by northern blot analysis in human adult SI (Peter et al. 1997), but whether FEV is expressed in human SI-NETs is not known. Using qRT-PCR, we analyzed $F E V$ expression in matched normal and tumor samples from the

Table 1 Characteristics of patients with well-differentiated neuroendocrine tumors of the small intestine

\begin{tabular}{|c|c|c|c|c|c|c|c|}
\hline & $\begin{array}{l}\text { Primary } \\
\text { site }\end{array}$ & $\begin{array}{l}\text { Lymph node } \\
\text { metastasis }\end{array}$ & $\begin{array}{l}\text { Liver } \\
\text { metastasis }\end{array}$ & $\begin{array}{l}\text { Serum CHGA } \\
(\mathrm{ng} / \mathrm{ml})\end{array}$ & $\begin{array}{l}\text { Urine } 24 \text { h } \\
\text { 5-HIAA (mg/24 h) }\end{array}$ & $\begin{array}{l}\text { Carcinoid } \\
\text { syndrome }\end{array}$ & $\begin{array}{l}\text { MEN I } \\
\text { syndrome }\end{array}$ \\
\hline 1 & Ileum & Present & Present & 302.9 & 63.9 & Yes & No \\
\hline 2 & Ileum & Present & Present & 758.5 & 520.6 & Yes & No \\
\hline 3 & Ileum & Present & Present & 195.0 & 7.9 & No & No \\
\hline 4 & Ileum & Present & None & 24.1 & 7.9 & No & No \\
\hline 5 & Ileum & Present & Present & 130.0 & 108.5 & Yes & No \\
\hline 6 & Ileum & Present & Present & ND & 16.5 & Yes & No \\
\hline 7 & Ileum & Present & Present & 310.0 & 14 & Yes & No \\
\hline 8 & Ileum & Present & None & 133.2 & 27.2 & No & No \\
\hline 9 & Ileum & Present & Present & 51.8 & 14.2 & Yes & No \\
\hline 10 & Ileum & Present & Present & ND & 86.6 & Yes & No \\
\hline 11 & Ileum & Present & Present & 1675.8 & 176.6 & Yes & No \\
\hline 12 & Ileum & Present & Present & 122.0 & 92 & Yes & No \\
\hline
\end{tabular}

CHGA, chromogranin A; 5-HIAA, 5-hydroxyindoleacetic acid; ND, not done; MEN, multiple endocrine neoplasia. Serum CHGA: normal $<36.4 \mathrm{ng} / \mathrm{ml}$; Urine $24-\mathrm{h} 5$-HIAA: normal $<6.0 \mathrm{mg} / 24 \mathrm{~h}$. 
12 patients described above (Table 1). Compared with those in the matched normal ileum, FEV expression levels were significantly elevated in SI-NE primary tumors (20-fold, $P<0.0001)$, NET lymph node metastases (35-fold, $P=0.004$ ), and NET liver metastases (22-fold, $P<0.0001$; Fig. 1). In contrast, $F E V$ expression levels in normal human colon and in colon cancer liver metastases were very low (Fig. 1). We did not observe any correlation between FEV expression level and tumor burden, as reflected by serum CHGA level, urine 24-h 5-HIAA level, or liver involvement (data not shown). These findings indicate that elevated $F E V$ expression is restricted to human SI-NETs that produce 5-HT, which may reflect utilization of a conserved pathway of NE differentiation in normal and neoplastic SI.

Overall, FEV expression was elevated in $96.5 \%$ (26/27) of human SI-NET samples when compared with the matched normal ileum. Specifically, FEV expression was increased in SI-NE primary tumors (11/11), NET lymph node metastases (6/7), and NET liver metastases (9/9). However, FEV expression levels in NET lymph node metastases $(P=0.72)$ and NET

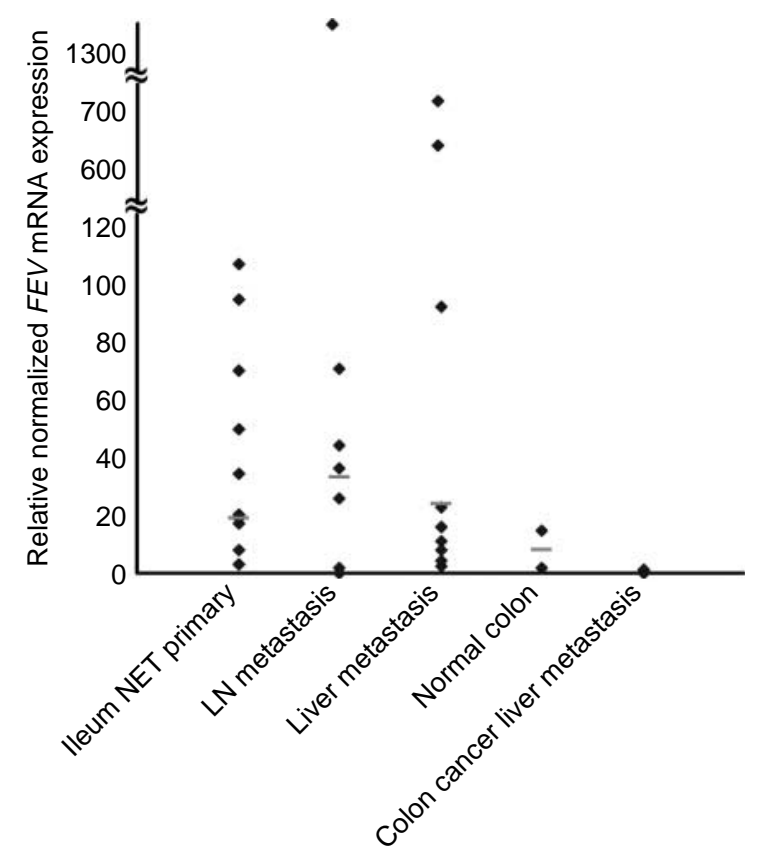

Figure 1 FEV is expressed in human well-differentiated NETs of the small intestine. Real-time TaqMan RT-PCR analysis shows FEV expression in matched ileum NET primary tumors $(n=11)$, lymph node metastasis $(n=7)$, and liver metastasis $(n=9)$. For comparison, FEV expression levels in normal colon $(n=2)$ and colon cancer liver metastasis $(n=5)$ are shown. Values are normalized to normal ileum samples $(n=12)$. Bar denotes median. liver metastases $(P=0.76)$ were not significantly different from those in SI-NE primary tumors (Fig. 1). $F E V$ expression levels in NE lymph node metastases were not significantly different from those in NET liver metastases $(P=0.92$; Fig. 1$)$. Because $F E V$ expression is detected in most human SI-NETs (i.e. in primary tumors as well as in their lymph node and liver metastases), but not in colon cancer liver metastases, we conclude that FEV is a novel SI-NET marker.

\section{FEV is expressed in 5-HT cells of normal mouse SI}

Low levels of Fev expression have been detected in rat SI by RNase protection analysis, but the identity of the cell type expressing $\mathrm{Fev}$ is not known (Fyodorov et al. 1998). No antibodies raised against Fev have been validated for immunohistochemical or immunofluorescence (IF) analysis. We and others found that the homeodomain transcription factor $\mathrm{Nkx} 2.2$ is required for the development of 5-HT-producing cells in mouse SI (Desai et al. 2008, Wang et al. 2009). In the CNS, $\mathrm{Fev}$ is necessary for 5-HT neuron development, functioning downstream of $\mathrm{Nkx} 2.2$ (Cheng et al. 2003), but whether Fev functions in enteroendocrine differentiation downstream of Nkx2.2 is not known. In Nkx2.2 mutant SI, cells that produce 5-HT are absent (Desai et al. 2008, Wang et al. 2009). Consistent with this, we found that mRNA levels of tryptophan hydroxylase 1 (Tphl), which catalyzes the ratelimiting step in 5-HT biosynthesis in the SI, were absent in $N k x 2.2(-/-)$ SI (Fig. 2A), which confirms our prior findings (Wang et al. 2009). Next, we analyzed $F e v$ expression in wild-type and $N k x 2.2$ $(-/-)$ SI. We readily detected $F e v$ expression in wildtype mouse SI (Fig. 2A). However, Fev mRNA levels were depleted in $N k x 2.2$ mutant SI, which lacks 5-HT cells (Fig. 1). These results suggest that Fev expression is dependent on Nkx2.2, and that Fev may be expressed in 5-HT cells in normal mouse SI.

To determine whether Fev-expressing cells give rise to 5-HT cells in the SI, we used recombination-based cell lineage tracing. The ePet-Cre transgenic mouse line uses the $F e v$ enhancer region to reliably direct the expression of Cre recombinase to 5-HT neurons in the CNS, faithfully recapitulating the spatiotemporal pattern of $\mathrm{Fev}$ expression in the CNS (Scott et al. 2005). Whether ePet-Cre mice drive expression of Cre recombinase in 5-HT-producing endocrine cells in the SI is not known. We crossed ePet-Cre mice with the Rosa26 reporter line to generate $\mathrm{R} 26 \mathrm{R}^{\mathrm{ePetCre}}$ mice. Cells and their descendants that utilize the Fev enhancer, even transiently, are permanently marked by $\beta$-gal. By IF analysis, we detected $\beta$-gal expression 

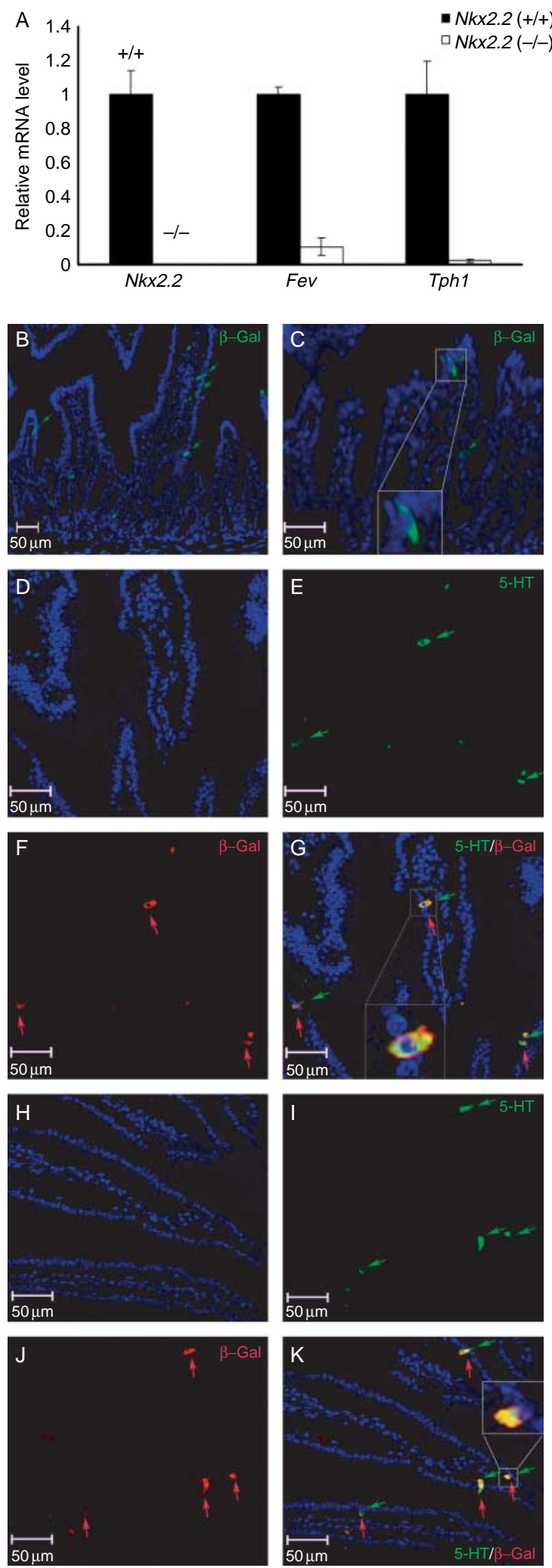

in rare cells located in the epithelium of $\mathrm{R} 26 \mathrm{R}^{\mathrm{ePetCre}}$ mouse SI, showing $\mathrm{Fev}$ is indeed expressed in the SI epithelium (Fig. 2B and C). Expression of $\beta$-gal was present throughout the crypt-villus axis of the SI in a pattern reminiscent of endocrine cells.

Next, to determine whether 5-HT-producing cells of the SI arise from Fev-positive cells, we performed double IF analysis. Serotonin is the most predominant hormone in the SI, and we detected co-localization of 5-HT-positive and $\beta$-gal-positive cells along the cryptvillus axis of the SI (Fig. $2 \mathrm{G}$ and $\mathrm{K}$ ). All 5-HT-producing cells in the SI also expressed $\beta$-gal (277/277), suggesting that, as in the CNS, 5-HT-producing cells in the SI arise from an Fev-expressing cell. These results suggest a conserved role for $\mathrm{Fev}$ in the differentiation of 5-HT-producing cells in the CNS and SI. Moreover, we concluded that Fev expression identifies 5-HT-producing cells in normal mouse SI.

\section{Fev (-I-) mice do not exhibit defects in SI endocrine cell number or hormone expression}

To elucidate the role of FEV in intestinal endocrine cell development, we analyzed the proximal SI (duodenum) in Fev (-I-) mice at E18.5. Routine H\&E staining showed no abnormalities in the appearance of Fev (-/-) SI (data not shown). As an initial screen for an intestinal endocrine phenotype, we assayed for the expression of the general NE marker CHGA by qRTPCR and IF analysis. We observed no difference in Chga mRNA level (Fig. 3A; $P=1.0$ ) or the number of CHGA-positive cells (Fig. 4A-C; $P=0.14$ ) in the SI of Fev (-I-) mice compared with the wild type.

Serotonin-producing cells are the most abundant intestinal endocrine cell type. When we assayed for 5-HT expression by IF analysis, we did not detect a difference in 5-HT cell number in the SI of Fev (-I-) mice compared with the wild type (Fig. 4D-F; $P=0.86$ ). Consistent with this, mRNA levels of Tphl, which catalyzes the rate-limiting step in 5-HT

Figure $2 \mathrm{Fev}$ is expressed in serotonin-producing cells of the mouse small intestine. Expression of indicated genes in the duodenum of $N k x 2.2(+/+)(n=3)$ and $N k x 2.2(-/-)(n=3)$ mouse embryos at E18.5 by real-time TaqMan RT-PCR (A). Compared with $N k x 2.2(+/+)$ intestine, near absence of Fev and Tph1 expression is observed in Nkx2.2 $(-/-)$ intestine (A). (B-K) Immunofluorescence experiments of duodenal sections obtained from adult R26R ${ }^{\text {ePetCre }}$ mice with the antibodies indicated. Immunofluorescent staining for $\beta$-gal shows ePetCre-induced LacZ expression in rare cells in the intestinal epithelium (B and $C$ ). (D-K) Co-expression of $\beta$-gal and 5-HT in cells of the intestinal epithelium. ( $D$ and $H$ ) DAPI identifies nuclei. Immunofluorescent staining for $5-\mathrm{HT}$ (E and I, green) and $\beta$-gal ( $F$ and $J$, red) with merged image ( $G$ and $K$ ) showing yellow double-stained cells. 


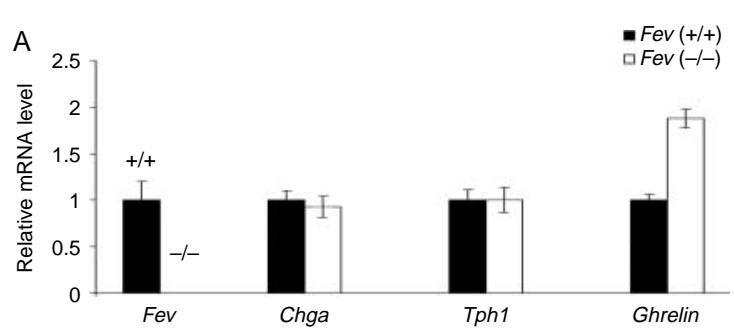

B

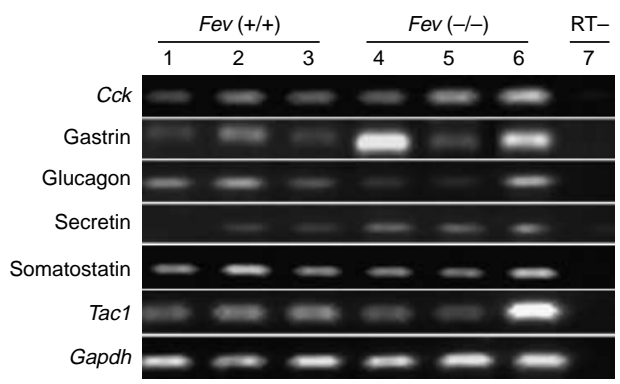

Figure 3 Expression of hormones in Fev (+/+) and Fev (-/-) intestine assayed by RT-PCR. Expression of indicated genes in the duodenum of Fev $(+/+)(n=3)$ and Fev $(-/-)(n=3)$ mouse embryos at E18.5 by real-time TaqMan RT-PCR $(A)$ or semi-quantitative RT-PCR (B). In Fev (-/-) intestine, ghrelin increased only 1.7 -fold $(P=0.08)$, but Chga or Tph1 expression did not change (A). Compared with Fev $(+/+)$ intestine (B, lanes 1, 2, and 3), no difference in the expression of $C c k$, gastrin, glucagon, secretin, somatostatin, Tac1, or Gapdh was observed in Fev (-I-) intestine (B, lanes 4, 5, and 6). No reverse transcriptase was used $(B$, lane 7$)$. Results represent mean \pm S.E.M.

biosynthesis in the gut, were unchanged in $\mathrm{Fev}(-/-)$ SI as assayed by qRT-PCR (Fig. 3A; $P=0.72$ ). We also examined the expression of $C c k$, gastrin, glucagon, secretin, somatostatin, and tachykinin precursor 1 (Tac1), which encodes for substance P, by RT-PCR and did not detect any differences in Fev (-/-) SI compared with the wild type (Fig. 3B). The glucagon gene encodes for preproglucagon, which undergoes post-translational processing to produce glucagon, GLP-1, and GLP-2.

In $N k x 2.2(-/-)$ mouse SI, an increase in ghrelinproducing cells is associated with depletion of most endocrine cell types (Desai et al. 2008, Wang et al. 2009). Since we found that Fev expression is diminished in $N k x 2.2(-/-)$ SI (Fig. 2A), we next investigated ghrelin expression in Fev (-/-) SI. As shown by qRT-PCR assay, ghrelin expression in $\mathrm{Fev}$ mutant SI increased only 1.7 -fold ( $P=0.08$; Fig. 3A). IF analysis showed no difference in the number of ghrelin cells in Fev $(-/-)$ SI $(P=0.66$; Fig. 4G-I). Although $\mathrm{Fev}$ is critical for the development of 5-HT neurons in the CNS, our analysis did not reveal any difference in the number of cells that produce 5-HT or other hormones in Fev (-I-) SI.

\section{Discussion}

Informed by observations from developmental neurobiology of the important role of the ETS oncogene family transcription factor Fev in the differentiation of 5-HT-producing neurons, we have shown here that FEV is expressed in SI-NETs - in the primary tumor as well as in lymph node and liver metastases. Every patient who underwent resection of the SI-NET had evidence of increased 5-HT elaboration. We have also shown that $\mathrm{Fev}$-expressing cells give rise to 5-HT-producing cells in normal mouse SI. Our findings suggest that FEV expression identifies 5-HT-producing cells in normal and neoplastic SI.

Recently, we and others showed that the homeodomain transcription factor Nkx2.2 functions in normal SI to control NE differentiation (Desai et al. 2008, Wang et al. 2009), and that it is expressed in SI-NETs (Wang et al. 2009). Given that Nkx2.2 and Fev act together in NE differentiation in the CNS (Cheng et al. 2003), we hypothesized that Fev might also play an important role, similar to Nkx2.2, in SI NE differentiation. Although $\mathrm{Fev}$ expression is restricted to 5-HT neurons in the CNS and is critical for their development (Hendricks et al. 2003), we detected no difference in the number of cells producing 5-HT or any other hormone in the SI of Fev (-/-) mice. Reasons for the differences in NE phenotype in the CNS versus SI in Fev $(-/-)$ mice despite the expression of Fev in 5-HT cells in both tissues may reflect differences in genetic redundancy between the CNS and SI. For example, transcription factors other than Fev might be required for the development of 5-HT-producing cells in the SI. Interestingly, we detected increases in neurogenin 3 and Pax4 mRNA levels in Fev (-/-) SI, which raises the possibility that increases in their expression may compensate for $\mathrm{Fev}$ loss in the SI (data not shown).

Because Fev expression is restricted to 5-HT neurons in the CNS (Scott et al. 2005), our analysis of Fev expression focused on normal and neoplastic SI, where 5-HT is the predominant hormone that is produced. However, Fev is expressed in malignant pancreatic NETs, which are believed to only rarely produce 5-HT (Duerr et al. 2008). Therefore, Fev could be expressed in NETs that produce hormones other than 5-HT. It is also possible that Fev is expressed in NETs derived from sites other than the SI and pancreas. Importantly, we found here that Fev expression is very low in colorectal liver metastases. Thus, our data show that Fev expression is not a general feature of adenocarcinomas. We also found that Fev-expressing cells give rise to gastrin/CCK cells 

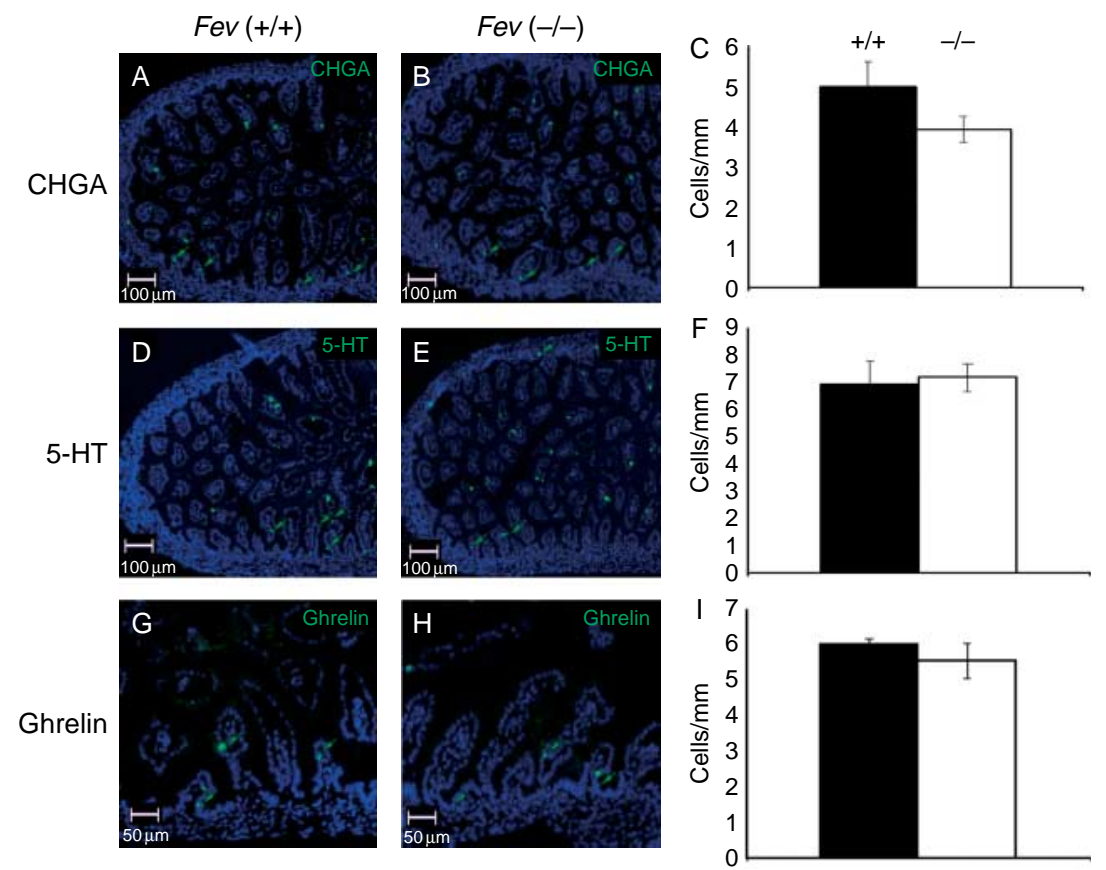

Figure $4 \mathrm{Fev}(-/-)$ mice do not exhibit defects in SI endocrine cell number. Immunofluorescence analysis of duodenal sections of control $(A, D$, and $G)$ and $F e v(-I-)(B, E$, and $H)$ mouse embryos at E18.5 with the antibodies indicated. (C, F, and I) Results of immunofluorescence experiments presented quantitatively. There is no difference in the number of CHGA- (C), 5-HT- (F), or ghrelinpositive (I) cells in Fev (-I-) intestine. The number of hormone-positive cells per millimeter of intestinal length of every fourth section of $\mathrm{Fev}(+/+)(n=3)$ and Fev $(-/-)(n=3)$ mouse intestine. Results represent mean \pm S.E.M.

in normal mouse SI (Supplementary Figure 1, see section on supplementary data given at the end of this article). Therefore, outside the CNS, Fev expression does not appear to be limited to 5-HT cells.

Fev, Nkx2.2, and Ascl1 share much in common. All three are pro-endocrine transcription factors essential for the development of 5-HT neurons in the mouse CNS (Pattyn et al. 2004). These transcription factors are also expressed in human SI-NETs, which characteristically elaborate 5-HT (Nakakura et al. 2005, Wang et al. 2009). Elaboration of 5-HT by SI-NETs stimulates tumor growth and causes the debilitating symptoms present in the carcinoid syndrome (Ishizuka et al. 1992, von Wichert et al. 2000). Thus, further study of FEV, Nkx2.2, and Ascl1 functions in SI-NETs has the potential to provide insight into the determinants of 5-HT production, which may result in a better understanding of NE tumorigenesis.

In addition to their link with the 5-HT phenotype in normal and neoplastic tissues, FEV, Nkx2.2, and Ascl1 have all been associated with tumorigenesis in diverse cancers. Ascl1 promotes tumor progression in lung cancers with NE features (Linnoila et al. 2000, Osada et al. 2005). $\mathrm{Nkx} 2.2$ promotes tumorigenesis in Ewing's sarcoma (Smith et al. 2006). FEV may also promote tumorigenesis in Ewing's sarcoma
(Peter et al. 1997, Ng et al. 2007). None of the patients included in our study had MEN I syndrome, so we are unable to speculate on any potential interaction between menin and FEV in SI-NETs. It is tempting to speculate that $\mathrm{FEV}, \mathrm{Nkx} 2.2$, and Ascl1 might cooperate to promote tumor progression in SI-NETs. Pro-endocrine transcription factors may have dual functions in SI-NETs. They may regulate NE differentiation and promote tumor progression. Therefore, investigations into the function of pro-endocrine transcription factors in appropriate NET models and cell lines may provide important insight into NET biology.

NETs comprise a heterogeneous group of neoplasms (Nakakura et al. 2007). Currently, NETs are diagnosed on the basis of morphology, expression of general NE markers (e.g. CHGA), and production of hormones; however, based on these findings alone, the particular NET type cannot be elucidated often. We have identified three developmental transcription factors Fev, Nkx2.2, and Ascl1 - expressed in SI-NETs (Nakakura et al. 2005, Wang et al. 2009). Although the expression pattern for each of these individual genes is known, the combinations of their expression have not been characterized in NETs. Further work may permit us to identify NETs not on the basis of morphology but on the basis of transcriptional 
programs. Such information may suggest the tumor location in patients with metastatic disease and unknown primary tumors. Moreover, such information may help provide insight into the lineage of NETs, which may result in the identification of NET stem cells or different classes of progenitors.

\section{Supplementary data}

This is linked to the online version of the paper at http://dx. doi.org/10.1677/ERC-09-0243.

\section{Declaration of interest}

The authors declare that there is no conflict of interest that could be perceived as prejudicing the impartiality of the research reported.

\section{Funding}

This work was supported by the James Ewing Oncology Fellowship Award (to E K Nakakura), American College of Surgeons Faculty Research Fellowship (to E K Nakakura), University of California Cancer Research Coordinating Committee (to E K Nakakura), UCSF Research Evaluation and Allocation Committee (REAC) Grant (to E K Nakakura), Novartis Oncology provided through the Cancer and Leukemia Group B Foundation (to E K Nakakura), the V Foundation for Cancer Research (to E K Bergsland, E K Nakakura), the Larry L Hillblom Foundation grant 2007/1B (to M S German), and the National Institutes of Health grants R01 DK021344 and P30 DK63720 (to M S German).

\section{Acknowledgements}

We thank the UCSF Mouse Pathology Core for help with tissue processing and Pamela Derish for editorial assistance.

\section{References}

Cheng L, Chen CL, Luo P, Tan M, Qiu M, Johnson R \& Ma Q 2003 Lmx1b, Pet-1, and Nkx2.2 coordinately specify serotonergic neurotransmitter phenotype. Journal of Neuroscience 23 9961-9967.

Desai S, Loomis Z, Pugh-Bernard A, Schrunk J, Doyle MJ, Minic A, McCoy E \& Sussel L 2008 Nkx2.2 regulates cell fate choice in the enteroendocrine cell lineages of the intestine. Developmental Biology 313 58-66.

Duerr EM, Mizukami Y, Ng A, Xavier RJ, Kikuchi H, Deshpande V, Warshaw AL, Glickman J, Kulke MH \& Chung DC 2008 Defining molecular classifications and targets in gastroenteropancreatic neuroendocrine tumors through DNA microarray analysis. Endocrine-Related Cancer 15 243-256.

Fyodorov D, Nelson T \& Deneris E 1998 Pet-1, a novel ETS domain factor that can activate neuronal $\mathrm{nAchR}$ gene transcription. Journal of Neurobiology 34 151-163.
Gierl MS, Karoulias N, Wende H, Strehle M \& Birchmeier C 2006 The zinc-finger factor Insm1 (IA-1) is essential for the development of pancreatic beta cells and intestinal endocrine cells. Genes and Development 20 2465-2478.

Hauso O, Gustafsson BI, Kidd M, Waldum HL, Drozdov I, Chan AK \& Modlin IM 2008 Neuroendocrine tumor epidemiology: contrasting Norway and North America. Cancer 113 2655-2664.

Hendricks TJ, Fyodorov DV, Wegman LJ, Lelutiu NB, Pehek EA, Yamamoto B, Silver J, Weeber EJ, Sweatt JD \& Deneris ES 2003 Pet-1 ETS gene plays a critical role in 5-HT neuron development and is required for normal anxiety-like and aggressive behavior. Neuron 37 233-247.

Ishizuka J, Beauchamp RD, Townsend CM Jr, Greeley GH Jr \& Thompson JC 1992 Receptor-mediated autocrine growth-stimulatory effect of 5-hydroxytryptamine on cultured human pancreatic carcinoid cells. Journal of Cell Physiology 150 1-7.

Jenny M, Uhl C, Roche C, Duluc I, Guillermin V, Guillemot F, Jensen J, Kedinger M \& Gradwohl G 2002 Neurogenin 3 is differentially required for endocrine cell fate specification in the intestinal and gastric epithelium. EMBO Journal 21 6338-6347.

Jensen J, Pedersen EE, Galante P, Hald J, Heller RS, Ishibashi M, Kageyama R, Guillemot F, Serup P \& Madsen OD 2000 Control of endodermal endocrine development by Hes-1. Nature Genetics 24 36-44.

Lee CS, Perreault N, Brestelli JE \& Kaestner KH 2002 Neurogenin 3 is essential for the proper specification of gastric enteroendocrine cells and the maintenance of gastric epithelial cell identity. Genes and Development 16 1488-1497.

Linnoila RI, Zhao B, DeMayo JL, Nelkin BD, Baylin SB, DeMayo FJ \& Ball DW 2000 Constitutive achaete-scute homologue-1 promotes airway dysplasia and lung neuroendocrine tumors in transgenic mice. Cancer Research 60 4005-4009.

Modlin IM, Lye KD \& Kidd M 2003 A 5-decade analysis of 13,715 carcinoid tumors. Cancer 97 934-959.

Modlin IM, Champaneria MC, Chan AK \& Kidd M 2007 A three-decade analysis of 3,911 small intestinal neuroendocrine tumors: the rapid pace of no progress. American Journal of Gastroenterology 102 1464-1473.

Modlin IM, Moss SF, Chung DC, Jensen RT \& Snyderwine E 2008 Priorities for improving the management of gastroenteropancreatic neuroendocrine tumors. Journal of the National Cancer Institute 100 1282-1289.

Nakakura EK, Sriuranpong VR, Kunnimalaiyaan M, Hsiao EC, Schuebel KE, Borges MW, Jin N, Collins BJ, Nelkin BD, Chen $\mathrm{H}$ et al. 2005 Regulation of neuroendocrine differentiation in gastointestinal carcinoid tumor cells by Notch signaling. Journal of Clinical Endocrinology and Metabolism 90 4350-4356. 
Nakakura EK, Venook AP \& Bergsland EK 2007 Systemic and regional nonsurgical therapy - what is the optimal strategy for metastatic neuroendocrine cancer? Surgical Oncology Clinics of North America 16 639-651, x.

Ng TL, O’Sullivan MJ, Pallen CJ, Hayes M, Clarkson PW, Winstanley M, Sorensen PH, Nielsen TO \& Horsman DE 2007 Ewing sarcoma with novel translocation $\mathrm{t}(2 ; 16)$ producing an in-frame fusion of FUS and FEV. Journal of Molecular Diagnostics 9 459-463.

Osada H, Tatematsu Y, Yatabe Y, Horio Y \& Takahashi T 2005 ASH1 gene is a specific therapeutic target for lung cancers with neuroendocrine features. Cancer Research 65 10680-10685.

Pattyn A, Simplicio N, van Doorninck JH, Goridis C, Guillemot F \& Brunet JF 2004 Ascl1/Mash1 is required for the development of central serotonergic neurons. Nature Neuroscience 7 589-595.

Peter M, Couturier J, Pacquement H, Michon J, Thomas G, Magdelenat H \& Delattre O 1997 A new member of the ETS family fused to EWS in Ewing tumors. Oncogene 14 1159-1164.

Schonhoff SE, Giel-Moloney M \& Leiter AB $2004 a$ Minireview: development and differentiation of gut endocrine cells. Endocrinology 145 2639-2644.

Schonhoff SE, Giel-Moloney M \& Leiter AB $2004 b$ Neurogenin 3-expressing progenitor cells in the gastrointestinal tract differentiate into both endocrine and non-endocrine cell types. Developmental Biology 270 443-454.

Scott MM, Wylie CJ, Lerch JK, Murphy R, Lobur K, Herlitze S, Jiang W, Conlon RA, Strowbridge BW \&
Deneris ES 2005 A genetic approach to access serotonin neurons for in vivo and in vitro studies. PNAS 102 16472-16477.

Shroyer NF, Wallis D, Venken KJ, Bellen HJ \& Zoghbi HY 2005 Gfi1 functions downstream of Math1 to control intestinal secretory cell subtype allocation and differentiation. Genes and Development 19 2412-2417.

Smith R, Owen LA, Trem DJ, Wong JS, Whangbo JS, Golub TR \& Lessnick SL 2006 Expression profiling of EWS/FLI identifies NKX2.2 as a critical target gene in Ewing's sarcoma. Cancer Cell 9 405-416.

Sussel L, Kalamaras J, Hartigan-O'Connor DJ, Meneses JJ, Pedersen RA, Rubenstein JL \& German MS 1998 Mice lacking the homeodomain transcription factor $\mathrm{Nkx} 2.2$ have diabetes due to arrested differentiation of pancreatic beta cells. Development 125 2213-2221.

Wang YC, Gallego-Arteche E, Iezza G, Yuan X, Matli MR, Choo SP, Zuraek MB, Gogia R, Lynn FC, German MS et al. 2009 Homeodomain transcription factor NKX2.2 functions in immature cells to control enteroendocrine differentiation and is expressed in gastrointestinal neuroendocrine tumors. Endocrine-Related Cancer 16 267-279. von Wichert G, Jehle PM, Hoeflich A, Koschnick S, Dralle H, Wolf E, Wiedenmann B, Boehm BO, Adler G \& Seufferlein T 2000 Insulin-like growth factor-I is an autocrine regulator of chromogranin A secretion and growth in human neuroendocrine tumor cells. Cancer Research 60 4573-4581.

Yang Q, Bermingham NA, Finegold MJ \& Zoghbi HY 2001 Requirement of Math1 for secretory cell lineage commitment in the mouse intestine. Science 294 2155-2158. 